\title{
Los Dientes del Estado. Control Criminal y Práctica Judicial en los Albores de la República Neogranadina, 1810 - 1840
}

\author{
José Wilson Márquez Estrada* \\ Universidad de Cartagena \\ jmarqueze@unicartagena.edu.co
}

Recibido: Septiembre de 2013

Aprobado: febrero de 2014

\begin{abstract}
Resumen
En este artículo describe y un analiza del control criminal y de las practicas judiciales en el contexto de la administración de justicia en el periodo de transición del régimen colonial al régimen republicano en la Nueva Granada. También resalta los cambios efectuados en este campo y los relaciona con el proceso de construcción de un nuevo orden social y de un nuevo Estado nacional. Igualmente analiza los mecanismos y estrategias utilizado para producir verdad en el proceso judicial colonial y republicano, resaltando que los escenarios judiciales son espacios de circulación de ideas y conceptos que nos permiten visualizar la mentalidad y los mecanismos de control social de una época. También describe el proceso de construcción del aparato judicial en el marco de la creación de un nuevo orden jurídico y constitucional
\end{abstract}

\footnotetext{
* Historiador y Magister en Historia de la Universidad Nacional de Colombia. Abogado de la Corporación Universitaria de la Costa. Profesor Asociado del Programa de Historia, Facultad de Ciencias Humanas, Universidad de Cartagena de Indias (Colombia). Miembro del grupo de investigación Frontera, Sociedad y Cultura del Caribe y Latinoamérica (Categoría B clasificación de Colciencias). Este artículo hace parte de un proyecto de investigación titulado: Administración de Justicia y Práctica Judicial en Colombia en el siglo XIX.
}

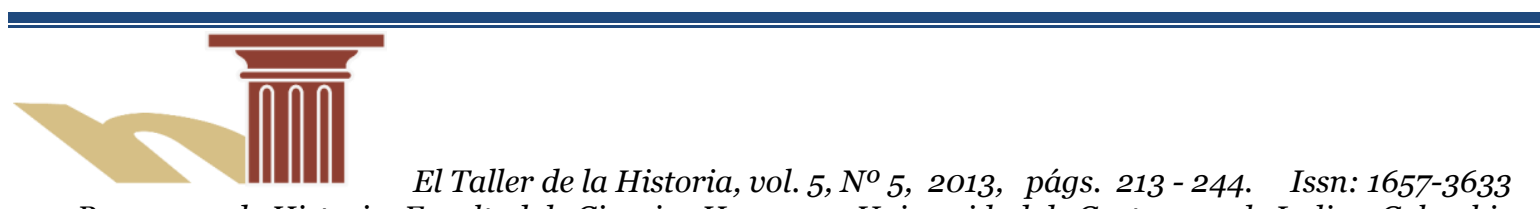

Programa de Historia, Facultad de Ciencias Humanas, Universidad de Cartagena de Indias, Colombia 
dentro del contexto de la construcción del Estado-Nación en las primeras tres décadas de la Republica y cuáles fueron las circunstancias y problemáticas que rodearon dicho proceso.

Palabras claves: Práctica judicial, Administración de justicia, Proceso judicial, Aparato judicial, Control criminal, Estado.

\title{
State Teeth. Criminal and Judicial Practice Control at the Dawn of the Republic of New Granada, 1810-1840
}

\begin{abstract}
This article is intended to provide a description and analysis of crime control and judicial practices in the context of the administration of justice in the period of transition from colonial to republican regime in New Granada and highlight the changes that were made in this field and relate them to the process of building a new social order and a new national state. Also be given an analysis of the mechanisms and strategies used to produce truth in the colonial and republican judicial process, noting that judicial scenarios are spaces of circulation of ideas and concepts that allow us to visualize the mentality and social control mechanisms of an era . There will also be a description of the construction process of the judiciary in the context of the creation of a new legal and constitutional order within the context of nation-state building in the early decades of the Republic, and what were the circumstances and problems surrounding the process.
\end{abstract}

Key words: Judicial practice, Administration of justice, Judicial process, Judiciary, Criminal control, State.

\section{Introducción}

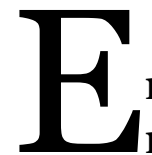

ntre las prácticas sociales en las que se refleja con mayor claridad el ordenamiento del poder, la mentalidad de una época y la estructura de un orden social, las prácticas jurídicas, o más precisamente las prácticas judiciales, están entre las más importantes. Las prácticas judiciales, es decir, la manera en que los hombres, se arbitran los daños y las responsabilidades, la forma en que se impone la reparación de un daño causado a otro o a la sociedad; nos definen los tipos de subjetividad, las formas de saber y las relaciones que se establecen entre los hombres en una determinada sociedad. ${ }^{1}$ En la práctica judicial se nos revela una época

\footnotetext{
${ }^{1}$ Michel Foucault, La verdad y las formas jurídicas, Barcelona, Gedisa, 2005, p.16.
} 
con sus formas de saber y de control social, siendo producto de las estructuras políticas que se les imponen a los sujetos.

Al final del régimen colonial, el gobierno español incrementó la represión a los desórdenes sociales, que eran apreciados como perturbaciones morales, mirada que estaba condicionada por la exagerada intervención de la Iglesia en los asuntos políticos. El rechazo a la represión se fue consolidando como uno de los factores más fuertes de incitación al levantamiento popular en el proceso independentista y que tuvo su máxima expresión en el rechazo a la práctica generalizada de la pena de muerte por las autoridades españolas, fuertemente aplicada en el período de la reconquista. $^{2}$ A esta situación de caos se le sumó un incremento de los índices de criminalidad que se manifiesta desde el mismo momento de la expulsión de las autoridades españolas en $1816 .{ }^{3}$ Verdadero ambiente de inseguridad que se traduce en desorden y en la falta de certeza sobre qué decisiones jurídicas eran validas y cuáles no, sobre cuáles instituciones judiciales estaban vigentes y cuáles no. ${ }^{4}$ Expresiones de la criminalidad que consistían fundamentalmente en la venganza y los ataques a la propiedad y a las personas que habían ostentado el poder en la sociedad colonial, situación que creó una sensación de caos que se propagó por toda la nación. ${ }^{5}$ Este escenario motivó el surgimiento inmediato de una nueva legislación en la Nueva Granada. Esta nueva legislación estuvo marcada inicialmente por un nuevo contexto político y social caracterizado por las confrontaciones internas entre las facciones federalistas y centralistas, santanderistas y bolivarianas.

La legislación penal española continuó rigiendo por algunas décadas después de la independencia, mientras se organizaba el poder judicial republicano, en este sentido se estableció que tanto en materia penal como en la civil rigieran las

\footnotetext{
2 Gilberto Parada García, "Orden y Revolución en le Ley Penal Colombiana. Un Debate Historiográfico", en Anuario Colombiano de Historia Social y de la Cultura vol.36, n. ${ }^{\circ}$, Bogotá, Universidad Nacional, 2009, pp.177-205.

${ }^{3}$ David Bushnell, El régimen de Santander en la Gran Colombia, Bogotá, El Áncora, 1985. Según Bushnell la criminalidad aumentó como consecuencia de la guerra de Independencia: "Durante el tiempo en que ésta se llevó a cabo en el territorio colombiano, desorganizó los mecanismos usuales del orden público; cuando terminó, dejó como corolario una turbulenta legión de vagabundos desertores y veteranos desadaptados”. p.71.

${ }^{4}$ Aura Peñas Felizzola, "Utilitarismo y Tradicionalismo en la Legislación Penal Republicana: el Código de 1837", en Revista Colombiana de Sociología n. ${ }^{\circ}$ 26, Bogotá, Universidad Nacional, 2006, pp.9-42.

${ }^{5}$ G. Parada García, “Orden y Revolución en le Ley Penal Colombiana”, p.182.
} 
leyes y decretos que en lo sucesivo dictare el nuevo Congreso Republicano. En este período de transición, las nuevas leyes republicanas coexistieron con las pragmáticas cédulas y leyes españolas vigentes hasta 1810 . Con relación a las sanciones penales, subsistieron la pena capital, la de azotes, la de vergüenza pública, la prisión, la confiscación, los trabajos forzados, el confinamiento, la privación o pérdida del oficio, y las multas, entre otras. Después se fueron tomando medidas tendientes a suprimir prácticas penales que se consideraban oprobiosas y que simbolizaban la arbitrariedad del dominio español. La Junta Suprema de Gobierno, cuando se dio el grito de independencia, que luego fue ratificado por la Constitución de Cundinamarca, abolió el uso legal de la tortura y en 1821, el vicepresidente de Cundinamarca abolió el Tribunal de la Inquisición. ${ }^{6}$

Dentro del marco legislativo republicano encontramos una pluralidad de leyes de diferente carácter (orgánicas, ordinarias, decretos, etc.). Las leyes orgánicas describen desde el punto de vista general los lineamientos de una política con relación a un tema específico, es así como encontramos diferentes leyes orgánicas de administración de justicia que intentan organizar todo lo relacionado con el tema de la justicia en los inicios de la República. ${ }^{7}$ En esta perspectiva, y a pesar de la ausencia de códigos penal y de procedimiento, se diseñó todo un conjunto de leyes que tenía que ver con la tipificación criminal y con su proceder, lo mismo que con las prácticas judiciales, acogiendo los principios del debido proceso, como la presunción de inocencia, derecho de defensa, imposibilidad de capturar o allanar un domicilio sin orden judicial. ${ }^{8}$ Con relación al juzgamiento del delincuente, los conceptos de jurisdicción y competencia se definían a partir de las constituciones y las leyes orgánicas del poder judicial. Entre 1821 y 1853, un período marcado por la construcción de un Estado unitario y centralista, la estructura de la administración de justicia estaba orientada desde lo más alto por la Alta Corte de Justicia, ${ }^{9}$ Corte

\footnotetext{
${ }^{6}$ Mario Aguilera, “Las Penas”, en Credencial Historia n. ${ }^{\circ}$ 148, Bogotá, 2002.

${ }^{7}$ Francisco Roberto Barbosa, Justicia: Rupturas y Continuidades. El Aparato Judicial en el Proceso de Configuración del Estado-Nación en Colombia: 1821-1853, Bogotá, Editorial Pontificia Universidad Javeriana, 2007, p.159. Rosa de Olmo, América Latina y su Criminología, Buenos Aires, Ed. Siglo XXI, 1984, p.78. Wolf Middendorf, Estudios de Criminología Histórica, Madrid, EspasaCalpe, 1983, p.54. Fernando Montovani, El Siglo XIX y las Ciencias Criminales, Temis, Bogotá, 1998, p.103.

${ }^{8}$ G. Parada García, “Orden y Revolución en le Ley Penal Colombiana”, pp.177-205.

${ }^{9}$ Denominación en la Constitución Política de 1821 y 1830., Carlos Restrepo (comp.), Constituciones Políticas Nacionales de Colombia, Bogotá, Universidad Externado de Colombia, 2003.
} 
Suprema de Justicia ${ }^{10}$ o Suprema Corte de la Nación, ${ }^{11}$ que ejercía jurisdicción sobre todo el territorio nacional y los tribunales superiores que tenían a su turno la jurisdicción del territorio -cantón, provincia o circuito-, en el cual administraban justicia. En síntesis, nos permitimos afirmar que, a pesar de que no se contaba con un código penal o de procedimiento criminal, en estos primeros años de la República, en la Nueva Granada se reguló todo el tema de la justicia penal a partir de la expedición de una serie de leyes que tipificaron conductas y sanciones. El ejemplo más claro nos lo proporciona el Congreso de Angostura cuando faculta al presidente de la República a "mitigar a favor de la humanidad, conmutar y aun perdonar penas aflictivas, aunque sean capitales con concepto previo del poder judicial”. ${ }^{12}$

En la Constitución Política de Cúcuta se establecieron varias disposiciones de carácter penal, tanto sustancial como procesal. ${ }^{13}$ Finalmente, la política criminal del Estado republicano se concretó en la elaboración del primer código penal que conoció la legislación penal en Colombia y que estaba enmarcado dentro de la doctrina de la Escuela Clásica italiana: el Código Penal de $1837,{ }^{14}$ que salió a la luz pública el 25 de junio del mismo año. ${ }^{15}$

En este artículo se pretende hacer una descripción y un análisis de las prácticas judiciales y de la administración de justicia criminal en el periodo de transición del régimen colonial al régimen republicano en la Nueva Granada y resaltar cuales fueron los cambios efectuados en este campo y relacionarlos con el proceso de construcción de un nuevo orden social y de un nuevo Estado nacional. También nos interesa identificar los cambios en la administración de justicia penal, en la práctica judicial y en los procedimientos de investigación criminal. De igual forma, se hará una descripción del proceso de construcción del aparato judicial en el marco de la creación de un nuevo orden jurídico y constitucional dentro del contexto de

\footnotetext{
${ }^{10}$ Denominación en la Constitución Política de 1832 y 1843. C. Restrepo, Constituciones Políticas.

${ }^{11}$ Denominación en la Constitución Política de 1853. C Restrepo, Constituciones Políticas.

12 Decreto expedido por Simón Bolívar el 18 de febrero de 1819. F. R. Barbosa, Justicia: Rupturas y Continuidades, p. 193.

${ }^{13}$ C. Restrepo, Constituciones Políticas, Constitución Política de Cúcuta de 1821. Artículo 158.

${ }^{14}$ Los siguientes son los códigos penales que se han producido en nuestro ordenamiento jurídico republicano: El primero fue el Código Penal de 1837, el segundo es el Código Penal de 1890, el tercero fue el Código Penal y Penitenciario de 1936, el cuarto fue el Código Penal de 1980 y el quinto es el Código Penal de 2000 (Ley 599 del 2000) que aún nos rige.
}

${ }^{15}$ A. Peñas Felizzola, "Utilitarismo y Tradicionalismo", p.25. 
la construcción del Estado-Nación en las primeras tres décadas de la Republica y cuáles fueron las circunstancias y problemáticas que rodearon dicho proceso.

El texto está dividido en cuatro partes, en la primera se describen y analizan las prácticas judiciales y la administración de justicia criminal en las postrimerías del periodo colonial, en la segunda parte se analiza el proceso de construcción de la administración de justicia penal en los inicios de la Republica, en la tercera parte se aborda el proceso de construcción del primer código penal republicano y en la cuarta parte se hace un análisis de las características de la práctica judicial republicana en este periodo. Por último, el artículo concluye con unas consideraciones finales.

\section{1.- Control criminal y práctica judicial en el orden colonial}

En el orden colonial las formas penales implementadas fueron muy confusas, explicable en parte por la inexistencia de un catalogo de leyes penales que permitiera su aplicación punitiva. Las Recopilación de las Leyes de Indias de 1680 y Las Siete Partidas del siglo XIII, fueron los textos que sirvieron de soporte de todo tipo de aplicación penal por parte de las autoridades judiciales. La legislación penal que impulsó la Corona en el Nuevo Reino de Granada estuvo marcada por los atributos de un mando confesional y patriarcal inspirado en la axiología del catolicismo y del ideal del ser cristiano. ${ }^{16}$ Situación que contrastaba con una variedad de expresiones punitivas fundamentadas en la costumbre en correspondencia con una estratificación social definida por el poder en términos de blancos, indios, negros, mestizos, zambos y mulatos. Se distinguía los delitos según el bien jurídico tutelado: la religión, el Rey, la persona, el honor, la vida, la propiedad, administración de justicia, etc. ${ }^{17}$ Delito y pecado estaban en un mismo plano, donde delitos contra las buenas costumbres como la sodomía y la bestialidad eran fuertemente reprimidos. ${ }^{18} \mathrm{En}$ síntesis, el homicidio, el abigeato, el hurto, el concubinato, el adulterio y el estupro

\footnotetext{
16 Véase José María Ots Capdequi, El Estado español en las Indias, México, FCE, 1957.

${ }^{17}$ Zoila Gabriel de Domínguez, "Delito y sociedad en el Nuevo Reino de Granada. Periodo virreinal 1740-1810”, en Universitas Humanística n. 8-9, Bogotá, Universidad Javeriana, 1974-1975.

18 Véase Leonardo Vega Umbasia, Pecado y delito en la colonia. La bestialidad como una forma de contravención sexual (1740-1808), Bogotá, Instituto Colombiano de Cultura Hispánica, 1994.
} 
son las expresiones más comunes de la criminalidad a finales del periodo colonial en el Nuevo Reino de Granada. ${ }^{19}$

El modelo de justicia implementado por la Corona en América estuvo marcado por un proceso judicial de corte inquisitorial. El sincretismo cultural se manifestó en el plano jurídico y en las prácticas judiciales donde se entrecruzaron los valores jurídicos de las castas blanca e india dando origen a lo que se conoce hoy como el derecho indiano. ${ }^{20}$ En este derecho, cada ley regulaba un delito en particular con su respetiva sanción y cuando se presentaba un vacío jurídico se penalizaba al arbitrio del juez, situación que convertía a este funcionario en el eje del proceso. ${ }^{21}$ En este contexto, la ley penal cumplía una función central en el mantenimiento del orden social y del statu quo, sus sanciones buscaban la intimidación individual y colectiva. Un derecho penal de claro corte religioso que operaba como soporte legal de un orden social definido por el catolicismo, quien le proporcionaba un sentido particular a las nociones de delito y de castigo, otorgándole plenos poderes al Rey para penar o perdonar. ${ }^{22}$ En este sentido, las trasgresiones que amenazaban el orden divino afectaban directamente el orden del Rey, por eso los delitos más graves eran denominados de lesa majestad. ${ }^{23}$

Un papel fundamental adquirieron los vecinos y súbditos del Rey en el mantenimiento del orden social colonial, donde el espacio social se convertiría en un verdadero escenario de vigilancia mutua. En la sociedad colonial, la imagen social, es la que en última instancia tiene un valor y un peso real en las relaciones inter-

\footnotetext{
${ }^{19}$ Gilberto Parada García, Ley formal y ley material: la ley penal y su codificación en la construcción del Estado colombiano, 1819-1837, tesis de Maestría, Departamento de Historia, Universidad Nacional de Colombia, Bogotá, 2011, p.43.

${ }^{20}$ Véase Antonio Dougnac Rodríguez, Manual de historia del derecho indiano, México, Universidad Nacional Autónoma de México, 1994.

${ }^{21}$ Véase Francisco Tomás y Valiente, El Derecho Penal de la Monarquía Absoluta. Siglos XVI, XVII y XVIII, Madrid, Tecnos, 1969.

22 Véase Joseph Marcos Gutiérrez, Práctica criminal de España, vol. III, Madrid, Oficina de Benito García y Cía., 1804.

${ }^{23}$ Véase Bartolomé Clavero, “Delito y pecado. Noción y escala de transgresiones”, Sexo barroco y otras trasgresiones, Madrid, Alianza, 1990.
} 
personales y colectivas. ${ }^{24}$ Esta situación permitió constituir al escándalo y al chisme en el principal mecanismo de control social. ${ }^{25}$

Las reformas borbónicas buscaron la formalización de la población mediante los registros y el estudio de sus potencialidades económicas, apuntando a la creación de una economía más productiva a partir del control de las actividades de los sujetos, señalando al ocio y a la vagancia como el principal mal de la sociedad. En este sentido, el principal objetivo borbónico era transformar a los súbditos del Rey en seres útiles y productores de riqueza para toda la sociedad. ${ }^{26}$

Con relación al derecho penal, el Rey Carlos III encargó en 1777 a Manuel de Lardizábal y Uribe la redacción de una codificación penal. ${ }^{27}$ La idea era poner a tono el derecho penal español con las nuevas tendencias reformistas del derecho penal europeo vinculado a la ilustración y que tenía como máximas figuras a Cesare Beccaria y a John Howard, quienes planteaban que la libertad y seguridad de los ciudadanos dependía en gran parte de la bondad de las leyes penales y procesales. ${ }^{28}$

A partir de la segunda mitad del siglo XviII el virreinato de la Nueva Granada vivió un crecimiento notable en su demografía. ${ }^{29}$ La criminalidad se disparó, convirtiéndose el robo en el delito más denunciado. Por ejemplo, a finales del período colonial, las calles santafereñas se volvieron peligrosas para sus habitantes, quienes podían ser robados a plena luz del día. Las casas de juego y las chicherías se constituyeron en el lugar de encuentro de amancebados, ladrones y vagos. ${ }^{30}$ Las autoridades borbónicas implementaron varios dispositivos de control social que se reflejaron en el aumento de hospicios, escuelas de trabajo, hospitales, casas de niños

\footnotetext{
${ }^{24}$ Diana Ceballos, "Gobernar las Indias. Por una historia social de la normalización”, en Historia y Sociedad n. ${ }^{\circ}$ 5, Medellín, Universidad Nacional, 1998, pp.149-195.

25 Adriana María Alzate, Suciedad y orden. Reformas sanitarias borbónicas en la Nueva Granada, 1760-1810, Bogotá, Universidad del Rosario/Universidad de Antioquia/ICANH, 2007, p.192.

${ }^{26}$ Nicolás González Quintero, "Se evita que de vagos pasen a delincuentes: Santafé como ciudad peligrosa (1750-1808)", en Anuario Colombiano de Historia Social y de la Cultura vol.37, n. ${ }^{\circ}$, Bogotá, Universidad Nacional, 2010, pp.17-44.

27 Véase Manuel Lardizábal y Uribe, Discurso sobre las penas, México, Porrúa, 1982.

${ }^{28}$ Michel Foucault, Vigilar y castigar. El nacimiento de la prisión, Buenos Aires, Siglo XXI, 2005, p.63.

${ }^{29}$ N. González Quintero, "Se evita que de vagos pasen a delincuentes”, p.26

${ }^{30}$ N. González Quintero, “Se evita que de vagos pasen a delincuentes”, p.39.
} 
expósitos y cárceles, el objetivo era someter y controlar a mal entretenidos, criminales y prostitutas. ${ }^{31}$

La administración de justicia penal a nivel local estaba en manos de los alcaldes ordinarios y era complementada por los alcaldes pedáneos y por los alcaldes de la santa hermandad, los primeros tenían competencia en algunos casos de hurtos y otros problemas en pequeñas jurisdicciones y los segundos tenían competencia en delitos cometidos fuera de las poblaciones. El ente máximo de la administración de justicia era la audiencia pretorial o cancillería y estaba compuesta por el virrey presidente, un regente, seis oidores que al mismo tiempo eran alcaldes de corte, dos fiscales y el alguacil mayor. ${ }^{32}$ Con relación a la jurisdicción a finales del siglo XVIII, la Nueva Granada estaba bajo la jurisdicción de la Real audiencia de Santafé y las provincias de Popayán y Guayaquil estaban bajo la jurisdicción de la Real audiencia de Quito. ${ }^{33}$ Había jueces para los asuntos civiles y criminales. A finales de ese siglo, se presentó una situación de congestión judicial en ciudades como la capital de virreinato por la cantidad de casos y por la falta de jueces. ${ }^{34}$

En la forma de administrar justicia se reflejaba el orden social colonial, por ejemplo, en los pueblos de indios la administración de justicia estaba en manos de las autoridades indígenas. Cuando el delito era demasiado grave el asunto pasaba a la Real audiencia, pero si sólo ameritaba el castigo de azotes o el trasquilar los cabellos, quedaba bajo la jurisdicción del corregidor indígena. ${ }^{35}$ La administración de justicia colonial debió adaptarse a las condiciones socio culturales del territorio y a

\footnotetext{
31 Véase Francisco Moreno y Escandón, "Estado del Virreinato de Santa Fe. Nuevo Reyno de Granada por el Dr. D. Francisco Antonio Moreno y Escandón. Año de 1772”, en Germán Colmenares (ed.), Relaciones e informes de los gobernantes de la Nueva Granada, t.I, Bogotá, Banco Popular, 1989.

${ }^{32}$ Francisco de Silvestre, "Apuntes reservados de Don Francisco Silvestre”, en Germán Colmenares (ed.), Relaciones e informes de los gobernantes de la Nueva Granada, t.II, Bogotá, Banco Popular, 1989, p.59.

${ }^{33}$ Catalina Villegas del Castillo, Del hogar a los juzgados. Reclamos familiares en los juzgados superiores en el tránsito de la colonia a la república: 180o-1850, Bogotá, Universidad de los Andes, 2006, p.11.

${ }^{34}$ N. González Quintero, "Se evita que de vagos pasen a delincuentes", p.163.

${ }^{35}$ Martha Herrera Ángel, Poder local, población y ordenamiento territorial en la Nueva Granada siglo XVIII, Bogotá, Archivo General de la Nación, 1996, p.15.
} 
la rígida diferenciación colonial entre "la república de españoles" y "la república de indios" contemplada en la Recopilación de Leyes de Indias. ${ }^{36}$

El proceso criminal español de corte inquisitorial se iniciaba con la práctica judicial principal de apertura del proceso que consistía en indagar por la historia personal de los implicados como una forma de comprender los motivos de la comisión de la conducta punible. El juez ordenaba al escribano que abriese cabeza de proceso dirigido a aclarar el delito y a identificar e individualizar a los implicados. Luego se procedía a la "información primaria" que incluía las primeras indagaciones efectuadas por el juez y la captura de los primeros sospechosos. ${ }^{37} \mathrm{El} \mathrm{juez} \mathrm{conti-}$ nuaba buscando pruebas contra el reo, luego se admitía las "repulsas" de la defensa y finalmente se publicaban los testimonios y demás pruebas, incluyendo la acusación formal del fiscal y el escrito de defensa. El juez podía dictar sentencia de tormento para intentar conseguir la confesión del reo. El proceso se cerraba con la pronunciación de la sentencia definitiva condenatoria o absolutoria. 38

Por su parte, y como testimonio del proceso penal indiano, el documento procesal criminal, se iniciaba con un auto donde se informaba muy sucintamente los hechos, la fecha, el nombre del funcionario y el motivo de la denuncia. En esta etapa se ubicaban los actores procesales, el lugar de la captura y el hecho motivo de la investigación. Los alguaciles eran los encargados de realizar las capturas, ya sea por medio de las rondas o por el aviso de algún vecino. Estos funcionarios son los que encuentran las evidencias y son los encargados de conducir a los sospechosos a la cárcel. ${ }^{39}$ La participación del vecindario era clave en la parte inicial del proceso y era el primer eslabón de la cadena procesal criminal. ${ }^{40}$ Pero eran los testigos los sujetos procesales esenciales y de ellos dependía el desarrollo del proceso. Los testigos cuentan con detalle cuales eran los objetos robados y la expresión de los im-

\footnotetext{
${ }^{36}$ Véase Julián de Paredes, Recopilación de leyes de los reynos de las indias, mandadas imprimir, y publicar por la majestad católica del rey Don Carlos II nuestro señor en Madrid, año de 1681, Madrid, Ediciones Cultura Hispánica, 1973.

${ }^{37}$ Natalia Marcela Guevara, "Ladrones públicos y notorios: el hurto entre los esclavizados de la Nueva Granada, 1750-180o", Memorias, IX Congreso Centroamericano de Historia, San José (Costa Rica), 2008, p.596.

${ }^{38}$ F. Tomás y Valiente, El Derecho Penal de la Monarquía Absoluta. Siglos XVI, XVII y XVIII, p.158

${ }^{39}$ N. González Quintero, “Se evita que de vagos pasen a delincuentes”, p.168

40 Julián Vargas Lesmes, La sociedad de Santafé Colonial, Bogotá, CINEP, 1990, p.346.
} 
plicados cuando eran capturados. ${ }^{41}$ Todo testigo era interrogado secreta y separadamente. Este debía cumplir con las condiciones de sexo, edad, capacidad y neutralidad en el proceso. Los principales medios de prueba después de los testimonios, eran el juramento, la confesión, la vista y evidencia del hecho y los peritajes. ${ }^{42}$

La cárcel era el centro de reclusión de los implicados mientras durara el proceso. El fallo determinaba cuál era el castigo: pena corporal, vergüenza pública, reclusión, trabajo en las galeras o trabajo forzado en el presidio. ${ }^{43}$ El castigo se extendía a los bienes materiales que el procesado tenía. ${ }^{44}$ Con relación al castigo público Nicolás González afirma lo siguiente:

La necesidad de hacer público el castigo sobre un sujeto que había cometido un robo que atentaba contra el orden social cumplía con una misión específica y una conexión con el resto de la sociedad, creando una serie de individualidades que se convertían en un referente social de forma simbólica y discursiva. El dolor desde una perspectiva religiosa ayudaba a la purificación del alma. A través de la conciencia de los sentidos, convertía al cuerpo del castigado en objeto de redención para su alma, por medio no sólo de su castigo, sino del ejemplo para todos los demás. ${ }^{45}$

A finales del siglo XVIII y comienzos del XIX, el número de causas pendientes en los juzgados inferiores y superiores desbordaron el número de jueces que podían fallarlas, dándose una acumulación de procesos que hacía más lento el trámite judicial, lo que motivó que en el año de 1803 el Virrey Pedro de Mendinueta solicitara al Rey ordenara la creación de otra sala en lo criminal. ${ }^{46}$

\footnotetext{
${ }^{41}$ N. González Quintero, "Se evita que de vagos pasen a delincuentes”, p.170.

42 A. Vela, De las instituciones penales, p.118.

43 Ismael Sánchez, Alberto de la Hera y Carlos Díaz, Historia del Derecho Indiano, Madrid, Ed. Mapfre, 1992, p.118.

${ }^{44}$ B. Patiño, Criminalidad, ley penal y estructura social en la provincia de Antioquia, 1750-1820, Medellín, IDEA, 1994, p. 25.

${ }^{45}$ N. González Quintero, "Se evita que de vagos pasen a delincuentes”, p.177.

46 Pedro de Mendinueta, "Relación del estado del Nuevo Reino de Granada, presentada por el Excmo. Sr. Virrey D. Pedro de Mendinueta a su sucesor el Excmo. Sr. Don Antonio Amar y Borbón. Año de 1803", en G. Colmenares, Relaciones e informes de los gobernantes de la Nueva Granada, t.III, pp.44-45. C. Villegas del Castillo, Del hogar a los juzgados, p.89.
} 
La administración de justicia colonial en el virreinato del Nuevo Reino de Granada no experimentó mayores cambios que los implementados por la casa borbónica en la segunda mitad del siglo XVIII y el proceso judicial continuo siendo lento y engorroso. En conclusión, el sistema jurídico penal del virreinato fue un sistema débil y poco uniforme, que contrastaba con fuertes tradiciones jurídicas, pero a pesar de esto, las leyes penales hispánicas prácticamente continuaron vigentes hasta 1837 y tan sólo se abolió la cuestionada institución de la Inquisición. ${ }^{47}$

\section{2.- La administración de justicia criminal en los primeros años de la república}

En los primeros años de la República se hace un intento por configurar una legislación penal independiente y diferente de la española como una iniciativa prioritaria del nuevo Estado y con base en experiencias legislativas de otros países. ${ }^{48}$ Estas iniciativas partían de un soporte constitucional, ${ }^{49}$ concretados en una serie de artículos de transición donde se orientaba a los jueces sobre las leyes que debían aplicar en casos concretos. Por ejemplo la Constitución de Antioquia al respecto decía:

Título IX. Disposiciones generales. 16. Todos y cada uno de los poderes, jueces, autoridades de la república observarán inviolablemente las leyes, ordenanzas, cédulas y reales órdenes que constituyen los códigos nacionales en todo aquello que no se hallen expresamente derogadas, o sean contrarias a la Constitución. En caso de duda consultará al Poder Legislativo. ${ }^{50}$

En materia penal, la ruptura con la legislación colonial fue un proceso lento que sólo se concretaría con la expedición del código penal de 1837. Pero mientras

\footnotetext{
${ }^{47}$ G. Parada García, Ley formal y ley material, p.46.

${ }^{48}$ Fernando Vélez, Datos para la historia del derecho nacional, Medellín, Imprenta del Departamento, 1891, p.75.

${ }^{49}$ Según François Xavier Guerra, los textos constitucionales de estos años fueron percibidos por los republicanos como la panacea que curaba todos los males sociales. François Xavier Guerra, Modernidad e independencias. Ensayos sobre las revoluciones hispánicas, México, Fondo de Cultura Económica, 2001, p 30.

50 Véase Miguel Antonio Pombo y José Joaquín Guerra, Constituciones de Colombia, Cuarta edición. Bogotá, Biblioteca Banco Popular, 1986.
} 
esto sucedía la Republica vivió toda una experiencia de transición legislativa en materia criminal donde el gran obstáculo a vencer era romper con la herencia colonial. Por su parte los jueces penales seguían utilizando la vieja legislación hispánica: la Recopilación de las Leyes de Indias de 1680 y Las Siete Partidas del siglo XIII, particularmente el libro séptimo que contenía las penas aplicables a los delincuentes. $\mathrm{Al}$ respecto dice Catalina Villegas que:

La práctica judicial de los primeros años de la República supuso por un lado, interpretar las legislación española redactada para otros pueblos de características distintas a la población mestiza que vivía en la Nueva Granada y la cual se insertaba en contextos sociales y culturales complejos; por el otro, se tradujo en la aplicación directa de las constituciones, en tanto expresaban una creación jurídica autónoma e independiente. ${ }^{51}$

En este orden de ideas, la independencia del gobierno español no significó la ruptura definitiva del derecho castellano y este, más otras reglamentaciones de estirpe medieval, regularon la vida de la nación hasta finales del siglo XIX. Durante todo este periodo convivió el derecho castellano con la producción legal del Congreso Nacional y, posteriormente, de las Asambleas legislativas de los Estados federados. Esta situación produjo el conflicto jurídico propio de la aplicación de las leyes antiguas con las más recientes. En un intento por salirle al paso a esta situación, el general Santander sancionó la ley de 13 de mayo de 1825 que reguló la prevalencia de las leyes locales sobre las castellanas. Al respecto de la sobrevivencia de las leyes castellanas en el orden jurídico republicano Armando Martínez y Orlando Pardo afirman lo siguiente:

Los primeros once años de nuestra vida política estuvimos regidos enteramente por leyes castellanas. La aparición de la Recopilación Granadina en 1844 sirvió para ordenar la producción local pero no implicó el destrone de la legislación española que siguió aplicándose subsidiariamente a nivel nacional y en los Estados hasta 1887, según se deduce de la lectura del artículo 15 de la ley 153 de ese año que categóricamente dice: "todas las leyes españolas están abolidas. ${ }^{52}$

\footnotetext{
${ }^{51}$ C. Villegas del Castillo, Del hogar a los juzgados, p.29

52 Armando Martínez Garnica y Orlando Pardo Martínez, El sistema jurídico en el Estado de Santander: 1857-1886, t.I, Bucaramanga, Universidad Industrial de Santander, 2008, p.26.
} 
En materia criminal los procesos ocurridos durante los primeros años de la República terminaron resolviéndose según las leyes españolas, que de alguna manera no entraran en contradicción con las cartas constitucionales, cuyos textos, valga la pena resaltar, no eran ideológicamente puros, ya que al pretender refundar a las sociedades y a los individuos a través de la constitución, se acudió a disposiciones normativas de otros países consideradas dignas de ser emuladas. ${ }^{53}$ Pero igualmente vale la pena resaltar que en materia criminal la ruptura total con el ordenamiento jurídico colonial se produjo sólo con la expedición del Código Penal de 1837 .

La aplicación del recurso constitucional como carta de batalla en los litigios fue una estrategia recurrente de los abogados en las primeras dos décadas de la Republica. Los profesionales del derecho basaban sus defensas penales en el articulado constitucional, esto es una característica fundamental de ruptura con la tradición jurídica de los abogados en la colonia que soportaban sus defensas en argumentos morales y religiosos. Luego con el avanzar del texto legislativo republicano, los abogados fundamentaron sus alegatos en la ley. ${ }^{54} \mathrm{Al}$ respecto de los profesionales del derecho en los primeros años de la República Víctor Manuel Uribe afirma:

Poco después del decisivo triunfo militar contra los ejércitos realistas en 1819, algunos jóvenes abogados empezaron a desempeñar un papel central en la burocracia y el congreso postcoloniales de la Nueva Granada. Surgió lo que se puede llamar una "generación de transición" de abogados burócratas de alto nivel y congresistas. Esta generación socialmente mixta desplazó a los abogados coloniales más antiguos que habían promovido la Independencia pero que, por diferentes razones, no lograron tener acceso a posiciones de liderazgo en el Estado postcolonial. 55

Ciertamente la profesión del derecho se convirtió en el siglo XIX en el soporte de las dinámicas de funcionamiento del Estado como consecuencia de la concentración del poder político en el sector civilista y legalista del Estado que había con-

\footnotetext{
${ }^{53}$ Véase Roberto Gargarella, Los fundamentos legales de la desigualdad. El constitucionalismo en América (1776-1860), Madrid, Siglo XXI, 2005.

${ }^{54}$ C. Villegas del Castillo, Del hogar a los juzgados, p.30.

55 Víctor Manuel Uribe Urán, Vidas honorables. Abogados, familias y política en Colombia: 17801850, Medellín, EAFIT/Banco de la República, 2008, p.182.
} 
solidado su triunfo sobre el sector militar o draconiana, el cual había sido fuertemente debilitado durante la campaña de reconquista de Pablo Morillo, donde fueron eliminados los mejores cuadros militares neogranadinos. ${ }^{56}$ La consolidación del triunfo del ala legalista y civilista dentro del Estado republicano se dio con llegada al poder del general Santander, después de la muerte de Bolívar. Santander logró imponer una imagen de hombre de leyes respetuoso del orden constitucional y legal, promoviendo la idea de la construcción del Estado desde el derecho. ${ }^{57}$ Esta estrategia es explicable a partir del principio fundamental de la construcción del Estado moderno según el cual el derecho es su máximo legitimador. En esta perspectiva, todo poder debe justificarse a través de una relación jurídica en correspondencia con una abstracción normativa y legal. Entonces, la legalidad sería el soporte de la legitimidad del poder. ${ }^{58}$

En la coyuntura de construir un nuevo orden social en los primeros años de la República, un nuevo ordenamiento jurídico penal se hizo cada vez más perentorio. Este nuevo orden penal serviría como soporte del nuevo poder político, en la proyección de un modelo de Estado republicano, a la vez que serviría como máximo dispositivo de control social, luego del cambio del poder del establecimiento colonial al republicano. Al respecto Gilberto Parada opina:

Los gobiernos republicanos hicieron uso de la ley penal con el fin de contrarrestar el accionar de sus enemigos políticos, dando pie al origen de la excepcionalidad de la ley penal durante la república. La idea concluyente muestra que la ley penal es un reflejo de las contradicciones de la sociedad neogranadina; especialmente evidencia las tensiones entre la modernidad y la tradición. ${ }^{59}$

La prioridad de la administración de justicia en los primeros años de la República, más precisamente entre los años 1810 y 1820, consistió en procesar a los

\footnotetext{
${ }^{56}$ Véase Allan Kuethe, Reforma militar y sociedad en la Nueva Granada, 1773-1808, Bogotá, Banco de la República, 1993.

${ }^{57}$ Véase David Bushnell, El régimen de Santander en la Gran Colombia, Bogotá, El Áncora Eds., 1985.

${ }^{58}$ Norberto Bobbio y Michelangelo Bovero, Origen y fundamentos del poder político, México, Grijalbo, 1985, p.33.

${ }^{59}$ G. Parada García, Ley formal y ley material, p.11.
} 
opositores de los regímenes políticos. ${ }^{60}$ En este sentido, la administración de justicia en materia penal se convirtió en este periodo en un verdadero dispositivo de dominación y de persecución de la oposición por parte de los poderes establecidos.

Con la Ley de abril 8 de $1826^{61}$ los legisladores buscaron regular la situación de las causas civiles y criminales que se interpusieron entre 1810 y 1820 , en un ambiente de confrontación política. El tema penal sólo se solucionaría con la expedición de un código penal y este fue propuesto por el parlamento entre 1826 y 1827 , pero fue rechazado por el ejecutivo. En términos generales la justicia penal había avanzado en comparación con el antiguo régimen a pesar de que algunos adelantos republicanos fueron truncados durante el mandato de Simón Bolívar, empeñado en perseguir las innovaciones efectuadas por Francisco de Paula Santander. ${ }^{62}$ A nivel judicial, y en correspondencia con un modelo de Estado que se construía desde el centro, se centralizó y controló la justicia desde la capital de la Republica, donde se ubicó el máximo tribunal de la jurisdicción ordinaria y desde allí se controlaron las decisiones adoptadas por los jueces inferiores en otros lugares del país. Todas las causas penales en donde se hubiera dado un fallo condenatorio eran remitidas a la Corte de Apelaciones para ser sometidas a revisión, en este sentido, las sentencias condenatorias en materia penal de los jueces de cantón o de provincia pasaban necesariamente por Bogotá. ${ }^{3} \mathrm{Al}$ respecto del proceso de justicia transicional en matera penal que vivió la República en sus primeros años Gilberto Parada plantea que no hubo realmente ningún progreso:

Esta primera producción de la legislatura republicana en el ramo judicial procedimental presenta dos aspectos innovadores, si se compara con el pasado hispano: uno fue la supresión de los alcaldes de la Santa Hermandad y el segundo fue la centralización de las funciones judiciales en el tribunal superior la Corte Suprema-, que debía revisar los asuntos de los juzgados de provincia, asunto que ahondó la sensación de caos o de anarquía con la que se caracteriza el momento de transición de la justicia colombiana entre 1819 y 1837, si queda

\footnotetext{
${ }^{60}$ C. Villegas del Castillo, Del hogar a los juzgados, p.21.

${ }^{61}$ Lino de Pombo, Recopilación de leyes de la Nueva Granada, formada i publicada en cumplimiento de la lei de 4 de mayo de 1843 i por comision del poder Ejecutivo, Bogotá, Imprenta de Zoilo Salazar, 1845.

${ }^{62}$ G. Parada García, Ley formal y ley material, p.57.

${ }^{63}$ C. Villegas del Castillo, Del hogar a los juzgados, p.23.
} 
en pie la idea que fueron pocas las transformaciones llevadas a cabo por los republicanos en la esfera del derecho penal. ${ }^{64}$

En los comienzos de la República la línea divisoria entre el poder ejecutivo y el poder judicial al parecer no era muy clara. Por ejemplo, el vicepresidente Santander dio a los jefes políticos de los cantones algunas facultades jurisdiccionales, esta situación llegó a su fin con la expedición de la Ley del 11 de mayo de 1825 que marcaría definitivamente la división entre estos dos poderes del Estado. 65

La situación judicial en los primeros años de la Republica sólo se aclararía definitivamente el 10 de mayo de 1834 con la expedición de la Ley orgánica de los tribunales y juzgados que regularía de manera concreta y concisa el funcionamiento de la administración de justicia. La estructura del aparato judicial se montó sobre la estructura político-administrativa, entonces provincias, cantones y parroquias tenían su propia jurisdicción donde tenían competencia los jueces republicanos, los tribunales superiores o cortes de apelación, los jueces de cantón y los jueces parroquiales. Por su parte, la Corte Suprema de Justicia no asumió funciones como máximo tribunal de la administración de justicia, sino que fue constituida para juzgar altos funcionarios del Estado. ${ }^{66}$ Este fue el primer mapa judicial republicano.

\section{3.- El Código penal de 1837}

La sociedad colombiana se da su primer código penal en 1837, que vendría a cumplir el papel fundamental de orientar las conductas sociales del ciudadano neogranadino. Al respecto dice Gilberto Parada que

Entre 1826 y 1827 el proyecto de código penal colombiano fue aprobado por una de las cámaras legislativas, pero fue rechazado por el ejecutivo. En 1833, el Consejo de Estado en su sesión del 21 de marzo eligió, para la preparación de un nuevo proyecto de código penal, a los consejeros José Ignacio de Márquez

\footnotetext{
${ }^{64}$ G. Parada García, Ley formal y ley material, p.50.

65 Armando Martínez Garnica, La agenda de Colombia. 1819-1831, t.I, Bucaramanga, Universidad Industrial de Santander, 2008, p.126

${ }^{66}$ L. de Pombo, Recopilación de leyes de la Nueva Granada.
} 
(quien ejerció como presidente del consejo), Vicente Azuero, Manuel Benito Rebollo, Manuel Mosquera, Bernardino Tobar, Salvador Camacho y José Manuel Restrepo; durante julio de 1833 ya se estaba discutiendo el articulado del proyecto que fue sancionado en 1837 y entró en vigencia un año después de la sanción presidencial. ${ }^{67}$

Este proceso de codificación estaba contextualizado con una ola codificadora y de renovación jurídica que se vivía en occidente. ${ }^{68}$ Los procesos de codificación penal que vivió América Latina en este período son la expresión de una historia de mundialización política de las ideas ilustradas. ${ }^{69}$ En este sentido, la ley penal colombiana está inscrita en una historia de las leyes penales en Euroamérica, igual que la administración de justicia y el control social; en una época marcada definitivamente por los cambios sociales y políticos. En esta perspectiva, podemos afirmar que la expedición del primer código penal colombiano pertenece a una historia de la codificación en occidente. Con relación a este tema Camilo Escobar y Adolfo Maya expresan que:

La historia del código penal es también la de ideas políticas que se mundializan, de granadinos que se hacen cosmopolitas, de obras jurídicas que circulan sin referentes nacionalistas, de ilustrados que se citan en Euroamérica, de textos que se estudian ampliamente entre intelectuales de ambos mundos, de prácticas pedagógicas en consonancia con las culturas políticas y de planes de estudio del espesor de las diferencias políticas. ${ }^{70}$

El punto de partida de la codificación penal latinoamericana, según el jurista argentino Eugenio Raúl Zaffaroni, fue el año de 1830, en ese año se promulgó el

\footnotetext{
${ }^{67}$ G. Parada García, “Orden y Revolución en le Ley Penal Colombiana”, p.188.

68 Marco Palacios, Parábola del liberalismo, Bogotá, Ed. Norma, 2002, pp.13-14. Palacios ha señalado tal fenómeno como parte de la cultura política que se arraigó con la aparición del republicanismo en Colombia y en el que uno de sus componentes sustantivos ha sido el control de la población a través de la ley penal. Recuerda Palacios cómo la distinción entre lo que el autor designa como país legal y país real ha tornado en una disputa por los valores sociales que deben prevalecer en el ámbito jurídico.

${ }^{69}$ Juan Escobar Villegas, y Adolfo Maya Salazar, "Legislar y Codificar en la Nueva Granada. Historia de una Cultura Política Mundializada en el siglo XIX”, en Co-herencia vol. 5, n. ${ }^{\circ} 8$, Medellín, Medellín, Eafit, 2008, pp.149-181.

${ }^{70}$ J. Escobar Villegas y A. Maya Salazar, “Legislar y Codificar en la Nueva Granada”, p.181.
} 
código penal de Bolivia, conocido como el código de Santa Cruz, y también el código penal del Imperio del Brasil; el código penal de Nicaragua de 1830 y el código Livingston de Guatemala de 1836. En la península ibérica apareció un proyecto de código en 1822 que entraría en vigencia solo hasta 1848; en Portugal, el código penal data de 1852.71 En este contexto surge el Código Penal Colombiano de 1837.

La nueva legislación neogranadina hace erosionar las viejas leyes españolas, principalmente en el terreno del derecho constitucional, pero igualmente en el derecho penal, es así como el nuevo código penal rompe la legislación penal colonial. El código penal irrumpe en este nuevo escenario desbaratando el viejo orden jurídico, dentro de un nuevo marco cultural del derecho, contribuyendo al surgimiento de una legalidad moderna en la región. La irrupción de este nuevo proyecto codificador es de notable importancia, no solo porque contribuye al abandono gradual del imaginario y la cultura legal del antiguo régimen, sino por el impacto que generó en la nueva vida social. ${ }^{72}$ En suma, en esta simbología jurídica de origen ilustrado, lo que importaba era romper con lo antiguo y olvidar las ataduras, pese a que los lazos vinculantes de la tradición y la modernidad del derecho no habían sido cortados, aunque es innegable que este nuevo código planteó un acto de ruptura con el pasado y un modo nuevo de concebir el derecho.

Sin embargo, lo que es igualmente evidente es que este proyecto, a pesar de su propósito revolucionario, contenía elementos tradicionales que son el reflejo de que la ruptura no había sido total, esto se manifiesta en la presencia de ideas religiosas en esta codificación como evidencia del contraste moderno tradicional de este proyecto. Aura Helena Peñas plantea lo siguiente al respecto:

El artículo 30 del primer código penal sancionado en Colombia, discutido y revisado durante más de tres años por los legisladores granadinos, dispone que "ninguna condenación podrá ser ejecutada en domingo, ni en día de fiesta de ambos preceptos, ni en los de la semana santa”. Igualmente plantea que el ceremonial penal de los condenados a penas corporales": "los reos irán acompañados de los ministros de la religión, del subalterno de justicia que presida la ejecución, del escribano y alguaciles, en traje de luto, y de la escolta correspon-

\footnotetext{
${ }^{71}$ Raúl Zaffaroni y Manuel Rivacoba, Siglo y medio de codificación penal en Iberoamérica, Valparaíso, Ed. Edeval, 1980, pp.13-43.

72 Víctor Manuel Uribe-Urán, “Derecho y cultura durante la 'era de la revolución' en México, Colombia y Brasil, 1750-1850: La Génesis de lo público y lo privado”, en María Teresa Calderón y Clément Thibaud (coords.), Las revoluciones del Mundo Atlántico, Bogotá, Universidad Externado de Colombia / Taurus, 2006, p.293.
} 
diente" y termina, con relación a la pena de muerte, planteando todo un ritual de simbología religiosa: "Los reos condenados a muerte serán conducidos al suplicio con túnica y gorro negro, y con las manos atadas por delante con una cuerda, cuyo extremo llevará el ejecutor de la justicia vestido de negro. Si el delincuente fuere asesino, llevará la túnica blanca y ensangrentada; si traidor, irá descalzo, la túnica hecha pedazos y las manos atadas a la espalda; si parricida, irá igualmente descalzo, con la túnica blanca ensangrentada y desgarrada, con una cadena al cuello y con las manos atadas a la espalda. ${ }^{73}$

Otro aspecto importante que ha sido tema de debate, con relación al código de 1837, es el perfil utilitarista de este proyecto codificador. La combinación de aspectos utilitaristas y tradicionalistas en los códigos penales del siglo XIX fue una constante se mantuvo hasta 1936, pero que se inició con el Código Penal de 1837. Esta naturaleza hibrida que contenía aspectos del legalismo francés e italiano con marcados propósitos religiosos, tiene su origen en el pensamiento de uno de los filósofos de mayor influencia en el siglo XIX colombiano: Jeremías Bentham. En este sentido, el Código Penal de 1817, se mueve entre ideas legalistas y la idea de conservar un orden social promovido por el catolicismo. La estructura sancionatoria de este proyecto era notoriamente benthamista, ya que establecía disposiciones de notable origen iusnaturalista religiosa como el hecho de prohibir las ejecuciones el día domingo, por ser día de guardar o en Semana Santa o si el condenado estaba de luto por la muerte de su padre o madre o si estaba gravemente enfermo o demente. También planteaba la no prescripción de ciertos delitos como el de traición, parricidio, asesinato e incendio por ser especialmente lesivos al bien común y por ser una amenaza para la sociedad y la República. En esta perspectiva, el pensamiento utilitarista marcó definitivamente el carácter del Código Penal de 1837. El pensamiento de Bentham fue apropiado por Francisco de Paula Santander ${ }^{74}$ y José Ignacio de Márquez, cofundadores de la República, como recurso político y de técnica legislativa para lograr la implantación definitiva de las ideas republicanas francesas y del liberalismo individualista inglés respecto del Estado. Pero, simultá-

\footnotetext{
${ }^{73}$ A. Peñas Felizzola, "Utilitarismo y Tradicionalismo en la Legislación Penal Republicana”, p.36.

${ }^{74}$ Luis López Domínguez, Administraciones de Santander, 1834-1835, Bogotá, Ed. Fundación para la Conmemoración del Bicentenario del Natalicio y Sesquicentenario de la Muerte del General Francisco de Paula Santander, Bogotá, 1990, p.26.
} 
neamente, los redactores combinaron el utilitarismo de Bentham con ideas de estirpe netamente tradicionalista, arraigadas en la moralidad católica. ${ }^{75}$

La estructura normativa del Código Penal de 1837 estaba compuesta por 919 artículos organizados en cuatro libros: el primero estuvo dedicado a los delitos y las penas; el segundo, a los delincuentes, la "graduación" de los delitos y la aplicación de las penas; en el tercero se organizaron los delitos y las culpas contra la sociedad y la aplicación de sus penas; el cuarto incluyó delitos y culpas contra los particulares y sus penas. Se clasifican los castigos en penas corporales y no corporales. Las penas corporales fueron: 1 . La de muerte; 2 . La de trabajos forzados; 3 . La de presidio; 4. La de reclusión en una casa de trabajo; 5 . La de vergüenza pública; 6 . La de prisión; 7. La de expulsión del territorio de la República; 8. La de confinamiento en un distrito parroquial, cantón o provincia determinada; 9. La de destierro de un lugar o distrito determinado. Las penas no corporales fueron: 1. La declaración expresa de infamia; 2. La privación de los derechos políticos y civiles; 3. La suspensión de los mismos; 4. La sujeción a la vigilancia de las autoridades; 5. La inhabilitación para ejercer empleo, profesión o cargo público en general, o en clase determinada; 6. La privación de empleo, pensión, profesión, o cargo público; 7. La suspensión de los mismos; 8. El arresto; 9. El apercibimiento judicial; 10. La obligación de dar fianza de buena conducta; 11. La multa; 12. La pérdida de algunos efectos, cuyo importe se aplique como multa. Todas las penas fueron adoptadas del código penal español de 1822, excepto la de vergüenza pública, que ya era una pena prácticamente eliminada de los códigos europeos, y la de suspensión de los derechos civiles y políticos, llevada del código napoleónico (artículos $6^{\circ}$ al $9^{\circ}$ ). ${ }^{76}$ Con relación a este espectro de influencias, Parada García plantea que:

Comparado con el código penal español de 1822, el de la Nueva Granada mantuvo muchos de los tipos penales que el código español prohibía. Luego, comparado con los códigos de los estados granadinos que aparecieron después de 1854, son pocos los cambios que se pueden señalar entre aquellos y el código nacional de 1837. Los Estados soberanos de Santander y Bolívar promulgaron sus códigos penales en 1872; en 1867 la Ley 222 aprobó el código penal para el

${ }^{75}$ A. Peñas Felizzola, “Utilitarismo y Tradicionalismo en la Legislación Penal Republicana”, p.23.

${ }^{76}$ A. Peñas Felizzola, “Utilitarismo y Tradicionalismo en la Legislación Penal Republicana”, p.24. 
pueblo soberano del Cauca y en ese mismo año fue expedido el código penal del estado soberano de Antioquia. ${ }^{77}$

El Código Penal de 1837, significó un distanciamiento de la legislación criminal del período colonial, pero también representó en el imaginario de la elite republicana el fin de una época caracterizada por el desorden de su normatividad punitiva. Igualmente su presencia contextualizaba con el gran impulso del movimiento de codificación del derecho penal que se había iniciado en Europa a finales del siglo XVIII y que había tomado fuerza en América a principios del siglo XIX.78

\section{4.- Práctica judicial republicana}

En el proceso criminal republicano la finalidad consiste en establecer la existencia del delito y el autor de la conducta punible. La naturaleza del proceso era acusatoria en la medida en que el fiscal intervenía activamente en el transcurso del proceso en representación del afectado y de la comunidad, señalando o no la ocurrencia del delito y el responsable del mismo. ${ }^{79}$ En los procesos por homicidio, el Estado iniciaba la acción penal de oficio, sin denuncia previa, ya que con esta conducta se consideraba lesionada la comunidad en general. ${ }^{80}$ Después de la denuncia el alcalde del lugar practicaba las pruebas para establecer el hecho delictivo y los responsables. Las declaraciones de los testigos eran fundamentales en el proceso y de gran consideración, tanto por la parte acusatoria como por la defensa. Fueron los veci-

\footnotetext{
${ }^{77}$ G. Parada García, “Orden y Revolución en le Ley Penal Colombiana”, p.189.

${ }^{78}$ Gisela Sedeillán, "Los delitos sexuales: la ley y la práctica judicial en la provincia de Buenos Aires durante el periodo de codificación del derecho penal argentino (1877-1872)", en Historia Crítica n. ${ }^{\circ}$ 37, Bogotá, Universidad de los Andes, 2009, pp.100-119.

${ }^{79}$ Los procesos criminales también pueden ser inquisitivos, cuando es la parte afectada la que le corresponde la carga de la prueba y debe probar su inocencia.

${ }^{80}$ Beatriz Patiño Millán, "Las mujeres y el crimen en la época colonial. El caso de la ciudad de Antioquia", en Las mujeres en la historia de Colombia, t.II, Bogotá, Presidencia de la RepúblicaEditorial Norma, 1995, pp.77-119.
} 
nos con sus testimonios protagonistas de primer orden en los procesos judiciales republicanos y terminaron siendo los mejores auxiliadores de la justicia. ${ }^{81}$

La solemnidad del proceso criminal puede observarse en los atuendos que llevaban jueces y fiscales. La Junta Suprema Central de Bogotá en 1810 procedió a regular la vestimenta que se deberían utilizar en los espacios judiciales los funcionarios de la justicia. El uniforme para los jueces y fiscales de la Sala de Gobierno y Hacienda del Tribunal de Apelaciones de Bogotá consistía en casaca y calzón negro, chopa y media blanca; en el cuello de las casacas bordadas las armas de la ciudad, y en la manga un pequeño bordado en oro. El uniforme de los jueces y fiscales de la Sala de Justicia era el mismo que el de la Sala de Gobierno a excepción del bordado que deberá ser de plata. Respecto de los abogados, se dispuso que usaran el mismo uniforme con solo un pequeño bordado de oro en la manga y bota de casaca..$^{82}$ Esta solemnidad del vestuario de los actores judiciales está cargada de una gran simbología de corte republicano, sobre todo en el periodo revolucionario donde se pretendía marcar la diferencia con la simbología de la justicia española.

En la parte probatoria del proceso republicano se admitían todo tipo de documentos escritos -personales u oficiales- así como la práctica de interrogatorios, pero los más frecuentes eran la declaración de testigos y de la parte demandada. Estas prácticas judiciales se adelantaban con previa formulación de cuestionario y las practicaba directamente el juez. Si la persona no podía asistir a la diligencia por causa de enfermedad o por estar domiciliado en otro lugar, el juez -mediante despacho comisorio- autorizaba a autoridad civil o eclesiástica a que llevara a cabo la diligencia. ${ }^{83}$ En los documentos procesales penales se visualiza la importancia que se la da a la condición social de los sujetos que intervienen en el proceso. Entonces, la fragmentación de la sociedad se manifiesta en el plano jurídico, donde fiscales, defensores, víctimas y victimarios indicaban su oficio y su casta como parte de los formalismos y protocolos del proceso criminal. ${ }^{84}$

\footnotetext{
${ }^{81}$ Germán Colmenares, "La ley y el orden social: fundamento profano y fundamento divino", en Boletín Cultural y Bibliográfico vol.XXVII, n. ${ }^{\circ}$ 22, Bogotá, Biblioteca Luis Ángel Arango, 1990, pp.319.

${ }^{82}$ Acta de la Junta Suprema del 23 de agosto de 1810 publicada en Diario Político de Santafé de Bogotá (1810-1811), n. ${ }^{\circ}$ XXVIII, Bogotá, noviembre 30 de 1810.

${ }^{83}$ C. Villegas del Castillo, Del hogar a los juzgados, p.46.

${ }^{84}$ G. Parada García, Ley formal y ley material, p.84.
} 
Otra práctica judicial de suma importancia en el proceso criminal republicano era la toma de la confesión, la cual fue reformada en la República en el artículo 167 de la Constitución de 1821, que estableció que "ninguno será admitido, ni obligado con juramento, ni con otro apremio, a dar testimonio contra sí mismo en causa criminal; ni tampoco lo serán recíprocamente entres sí, los ascendientes y descendientes y los parientes.". ${ }^{85}$ Para practicar esta diligencia, el alcalde se desplazaba con el escribano a las cárceles a tomarle la confesión a homicidas y trasgresores. Cuando se trataba de indios o de menores de edad se nombraba un Procurador Protector de Naturales o un Curador, respectivamente para que efectuara la diligencia. 86

La argumentación judicial utilizada por los diferentes actores del proceso republicano, a diferencia del proceso colonial, en los cuales la moral y la religión fundamentaron los alegatos, estaba soportada en las leyes y en la carta política. En este sentido el Estado republicano estuvo comprometido desde sus inicios con el desarrollo de una verdadera cultura de la ley. La ley entonces adquirió un valor importante en el lenguaje que se utilizó en los juzgados, siendo la representación de los ideales liberales de libertad e igualdad. Para los jueces y fiscales, el respeto y seguimiento del ordenamiento jurídico era el obedecimiento de los valores republicanos. Para el Estado, por su parte, la ley terminó siendo la herramienta más sofisticada para ejercer el control sobre los individuos y la sociedad. ${ }^{87}$

Después de la etapa probatoria, seguía la etapa de alegatos donde el fiscal del crimen conceptuaba si debía acusarse o no al sindicado. Los abogados, por medio de documentos escritos, exponían sus argumentos finales con relación al tema del proceso, después el juez emitía el fallo con sentencia absolutoria o condenatoria y con estricto apego a la ley. Ante estos fallos las partes podían apelar la decisión ante una autoridad judicial superior. ${ }^{88} \mathrm{En}$ el año 1847, el Estado ordenó que las decisiones judiciales proferidas por los distintos tribunales fueran publicadas en una edición mensual que se llamó Repertorio Judicial de la Nueva Granada, cuyo obje-

\footnotetext{
${ }^{85}$ Carlos Restrepo Piedrahita, Primeras Constituciones de Colombia y Venezuela, 1811-183o, Bogotá, Universidad Externado de Colombia, 1996, p.84.

${ }^{86}$ G. Parada García, Ley formal y ley material, p.83.

${ }^{87}$ G.Colmenares, “La ley y el orden social: fundamento profano y fundamento divino”, p.15

${ }^{88}$ C. Villegas del Castillo, Del hogar a los juzgados, p.47.
} 
tivo era hacer pública la actividad judicial de la República y el estado de la administración de justicia.

Uno de los bienes jurídicos de mayor valor en el periodo republicano era la vida y en correspondencia con el cuidado de este bien se profirieron los castigos más severos para buscar su protección. El homicidio voluntario se castigaba con la pena de muerte y el involuntario con cuatro a diez años de trabajo forzado en el presidio de Cartagena (Art. 605, Código Penal de 1837). Después del hecho homicida venía el médico legal a realizar el dictamen sobre las causas de la muerte y a continuación del dictamen, el escribano procedía a dejar constancia de que la víctima del homicidio no presentaba signos vitales. Al respecto Catalina Villegas nos ilustra el siguiente cuadro:

En el proceso por uxoricidio adelantado contra Francisco Díaz por presumirse su autoría en la muerte de su esposa, tras la valoración médica de Honorato Vila señalando que la occisa mostraba una fractura en la nariz, el escribano procedió a dejar la siguiente constancia: "...la llame à voces por su nombre y apellido tres veces delante de los que allí se hallaban y no contestó ni dio seña alguna de vitalidad; $y$ antes bien nos aseguramos así el facultativo como yo y los demás presentes que era difunta”. La formalidad de llamar a la difunta tres veces por su nombre y apellido constituía la forma mediante la cual se declaraba legalmente la muerte". 89

En cuanto a los modelos de presidio implementados en la primera mitad del siglo XIX en Colombia, podemos afirmar que se dieron dos modelos de diferente funcionalidad y connotación punitiva y jurídica: el modelo duro e implacable heredado de la Colonia y el de la institución prevista para el trabajo público, propio de la nueva visión decimonónica disciplinadora de la cárcel moderna. ${ }^{90} \mathrm{El}$ primero, es decir, el presidio colonial-republicano perduró hasta mediados del siglo XIX, mientras que el segundo, diseñado para la privación de la libertad en función de la obra pública rigió desde $1837 \cdot{ }^{91}$ En 1838 el presidente José Ignacio de Márquez ${ }^{92}$ se in-

\footnotetext{
${ }^{89}$ C. Villegas del Castillo, Del hogar a los juzgados, p.86.

${ }^{90}$ Véase Darío Melossi y Massimo Pavarini, Cárcel y Fábrica, los Orígenes del Sistema Penitenciario, Siglos XVI-XIX, Bogotá, Editorial Siglo XXI, 1985.

${ }^{91}$ Mario Aguilera, "La Administración de Justicia en el Siglo XIX", en Credencial Historia n. ${ }^{\circ} 136$, Bogotá, 2001, p.9.
} 
clinó por fortalecer el modelo penitenciario heredado de la Colonia y los reglamentó como establecimientos de trabajos forzados con jurisdicción nacional, esos fueron la fortaleza de Cartagena y la fortaleza de Chagres en Panamá. ${ }^{93}$

Es necesario resaltar que otro actor de suma importancia y protagonismo dentro del proceso criminal republicano fue el abogado. ${ }^{94}$ Con la ley orgánica del poder judicial que se expidió el 11 de mayo de 1825 se establecieron las particularidades que debían cumplir los abogados para intervenir en los juicios. El artículo 121 planteó los cuatro requisitos que debían acreditar los abogados para hacerse parte en una causa. El primero se refería a que el abogado debía haberse ejercitado en el foro, bajo la dirección de otro abogado que tuviese estudio abierto. En segundo término, asistir a lo menos una vez a la semana a las cortes de justicia o juzgados de primera instancia. En tercer lugar haber aprobado un examen en una escuela de abogados por tres abogados elegidos por las cortes de justicia. Por último, aprobar otro examen realizado por la Corte Superior y los fiscales. ${ }^{95}$ Finalmente, es preciso anotar que el abogado era una figura indispensable en todos los procesos y si el demandado no tenía recursos para pagar los servicios de este profesional, la justicia le nombraba un "abogado de pobres" para que lo asistiera en el proceso. ${ }^{96}$

\section{Consideraciones finales}

El carácter abierto de la institución judicial colonial permitió la participación de múltiples sujetos en el proceso judicial, haciendo que la figura del vecino, con su texto narrativo y su discurso, se convirtiera en el centro del escenario judicial y en el dispositivo más importante de producción de verdad, otorgándole más fuerza a su papel en el ejercicio del control social. En este sentido brillaron mecanismos de

\footnotetext{
92 Javier Ocampo López, “José Ignacio de Márquez, El Civilista”, en Credencial Historia n. ${ }^{\circ} 45$, Bogotá, Septiembre de 1993, pp.10-12.

93 José Wilson Márquez Estrada, "La Imposible Prisión. Sistema Penitenciario y Carcelario en el Estado Soberano de Bolívar: 1860-1880", en Palobra n. ${ }^{\circ}$ 11, Cartagena, Universidad de Cartagena, 2011, pp.198-216.

${ }^{94}$ V. M. Uribe-Urán, Vidas honorables, p.241. Uribe-Urán estima que en el año de 1806 había alrededor de 150 abogados en la Nueva Granada, la mayoría de ellos concentrados en Santafé.

${ }^{95}$ F. Roberto Barbosa, Justicia: Rupturas y Continuidades, p.211.

${ }^{96}$ C. Villegas del Castillo, Del hogar a los juzgados, p.44.
} 
regulación de la vida cotidiana en las ciudades y en las villas como la delación, la vigilancia y el chisme.

La actuación de los habitantes de la ciudad y de los miembros del aparato judicial se unió en un solo propósito donde la vergüenza, el castigo físico y el trabajo en el presidio dieron paso a una contraposición entre los seres virtuosos y los criminales.

Desde los inicios del régimen republicano hay un esfuerzo por parte del Estado por formalizar y organizar la administración de justicia y las prácticas judiciales. Este esfuerzo tiene el objetivo de poner orden a una institución que tenía un cierto perfil de anarquía desde tiempos coloniales y que nunca preocupó realmente a las autoridades españolas.

La práctica judicial republicana se modifica y perfecciona como tecnología de búsqueda de la verdad, dentro del contexto de modernización y formalización del aparato judicial, haciéndose más específico y detallado el proceso judicial en todas sus instancias, revelando un compromiso por parte del Estado republicano con una visión ilustrada del derecho y de la justicia. Prácticas que de alguna manera se ven permeadas por nuevas formas de producción de saber sobre el delito, el delincuente y el castigo.

En el período colonial como en el republicano, los procesos judiciales en general y las decisiones de los jueces, en particular, constituyeron intervenciones del Estado en todas las esferas de la vida social, incluyendo la esfera de la vida privada $\mathrm{y}$, en consecuencia, se consolidaron como un gran mecanismo de control social. Para el caso republicano la administración de justicia y el aparato judicial se consolidan como instrumentos activos dentro del proceso de construcción de ciudadanía, de nación y de Estado.

El proceso de transición de las prácticas tradicionales coloniales a las prácticas republicanas de corte ilustrado y moderno, fue lento pero seguro, y por momentos se revela una continuidad de las prácticas y de los procedimientos de origen colonial, como es el caso de la importancia de la figura del vecino y el valor otorgado a su declaración dentro del proceso, pero a mediados del siglo XIX, con el triunfo de las ideas liberales en el campo del derecho y de la administración de justicia; la transición había alcanzado el nivel de revolucionario con expresiones como la abolición de la pena de muerte y la desaparición del argumento religioso y moral dentro del discurso judicial y el énfasis creciente en el argumento legal y constitucional. 


\section{Bibliografía}

\section{Fuentes primarias impresas:}

Colmenares, Germán (comp.), Relaciones e informes de los gobernantes de la Nueva Granada, tomo III, Bogotá, Biblioteca del Banco Popular, 1989,.

Gutiérrez, Joseph Marcos, Práctica criminal de España, vol. III, Madrid, Oficina de Benito García y Cía., 1804.

Moreno y Escandón, Francisco, "Estado del Virreinato de Santa Fe. Nuevo Reyno de Granada por el Dr. D. Francisco Antonio Moreno y Escandón. Año de1772. Relaciones $e$ informes de los gobernantes de la Nueva Granada, tomo I, Ed. Germán Colmenares, Bogotá, Banco Popular, 1989.

Pombo, Lino de, Recopilación de leyes de la Nueva Granada, formada i publicada en cumplimiento de la lei de 4 de mayo de 1843 i por comision del poder Ejecutivo, Bogotá, Imprenta de Zoilo Salazar, 1845.

Pombo, Miguel Antonio, Guerra, José Joaquín, Constituciones de Colombia, Cuarta edición. Bogotá, Biblioteca Banco Popular, 1986.

Restrepo Piedrahita, Carlos (comp.), Constituciones Políticas Nacionales de Colombia, Bogotá, Universidad Externado de Colombia, 2003.

Restrepo Piedrahita, Carlos, Primeras Constituciones de Colombia y Venezuela, 18111830, Bogotá, Universidad Externado de Colombia, 1996.

Silvestre, Francisco, “Apuntes reservados de Don Francisco Silvestre”, en Germán Colmenares (comp.), Relaciones e informes de los gobernantes de la Nueva Granada, tomo II, Bogotá, Banco Popular, 1989.

Vélez, Fernando, Datos para la historia del derecho nacional, Medellín, Imprenta del Departamento, 1891.

\section{Fuentes Secundarias}

Aguilera, Mario, "La Administración de Justicia en el Siglo XIX", en Credencial Historia n. ${ }^{\circ} 136$, Bogotá, 2001.

Aguilera, Mario, “Las Penas”, en Credencial Historia n. ${ }^{\circ}$ 148, Bogotá, 2002.

Alzate, Adriana María, Suciedad y orden. Reformas sanitarias borbónicas en la Nueva Granada, 1760-1810, Bogotá, Universidad del Rosario / Universidad de Antioquia / ICANH, 2007. 
Barbosa Delgado, Francisco Roberto, Justicia: Rupturas y Continuidades. El Aparato Judicial en el Proceso de Configuración del Estado-Nación en Colombia: 1821-1853, Bogotá, Editorial Pontificia Universidad Javeriana, 2007.

Bobbio, Norberto y Bovero, Michelangelo, Origen y fundamentos del poder político, México, Grijalbo, 1985.

Bushnell, David, El régimen de Santander en la Gran Colombia, Bogotá, El Áncora, 1985.

Ceballos, Diana, “Gobernar las Indias. Por una historia social de la normalización”, en Historia y Sociedad n. ${ }^{\circ}$ 5, Medellín, Universidad Nacional, 1998, pp.149-195.

Clavero, Bartolomé, “Delito y pecado. Noción y escala de transgresiones”, Sexo barroco y otras trasgresiones, Madrid, Alianza, 1990.

Colmenares, Germán, "La ley y el orden social: fundamento profano y fundamento divino", en Boletín Cultural y Bibliográfico vol.XXVII, n. ${ }^{\circ} 22$, Bogotá, Biblioteca Luis Ángel Arango, 1990, pp. 3-19.

Domínguez, Zoila Gabriel de, "Delito y sociedad en el Nuevo Reino de Granada. Periodo virreinal 1740-1810", en Universitas Humanística n. ${ }^{\circ} 8-9$, Bogotá, Universidad Javeriana, 1974-1975.

Dougnac Rodríguez, Antonio, Manual de historia del derecho indiano, México, Universidad Nacional Autónoma de México, 1994.

Escobar Villegas, Juan Camilo y Maya Salazar, Adolfo León, "Legislar y Codificar en la Nueva Granada. Historia de una Cultura Política Mundializada en el siglo XIX”, en Co-herencia, Medellín, vol.5, n. ${ }^{\circ}$, Medellín, Eafit, 2008, pp.149-181.

Foucault, Michel, La verdad y las formas jurídicas, Barcelona, Gedisa, 2005.

Foucault, Michel, Vigilar y castigar. El nacimiento de la prisión, Buenos Aires, S. XXI, 2005.

Gargarella, Roberto, Los fundamentos legales de la desigualdad. El constitucionalismo en América (1776-1860), Madrid, Siglo XXI, 2005.

González Quintero, Nicolás Alejandro, "Se evita que de vagos pasen a delincuentes: Santafé como ciudad peligrosa (1750-1808)", en Anuario Colombiano de Historia Social y de la Cultura, vol.37, n. ${ }^{\circ}$, Bogotá, Universidad Nacional, 2010, pp.17-44.

Guerra, François Xavier, Modernidad e independencias. Ensayos sobre las revoluciones hispánicas, México, Fondo de Cultura Económica, 2001. 
Guevara, Natalia Marcela, "Ladrones públicos y notorios: el hurto entre los esclavizados de la Nueva Granada, 1750-180o", Memorias, IX Congreso Centroamericano de Historia, San José (Costa Rica), 2008.

Herrera Ángel, Martha, Poder local, población y ordenamiento territorial en la Nueva Granada -siglo XVIII, Bogotá, Archivo General de la Nación, 1996.

Kuethe, Allan, Reforma militar y sociedad en la Nueva Granada, 1773-18o8, Bogotá, Banco de la República, 1993.

Lardizábal y Uribe, Manuel, Discurso sobre las penas, México, Porrúa, 1982.

López Domínguez, Luis Horacio, Administraciones de Santander, 1834-1835, Bogotá, Ed. Fundación para la Conmemoración del Bicentenario del Natalicio y Sesquicentenario de la Muerte del General Francisco de Paula Santander, Bogotá, 1990.

Márquez Estrada, José Wilson, "La Imposible Prisión. Sistema Penitenciario y Carcelario en el Estado Soberano de Bolívar: 1860-1880", en Palobra n. ${ }^{\circ} 11$, Cartagena, Universidad de Cartagena, 2011, pp. 198-216.

Martínez Garnica, Armando, La agenda de Colombia. 1819-1831, tomo I, Bucaramanga, Universidad Industrial de Santander, 2008.

Martínez Garnica, Armando y Pardo Martínez, Orlando, El sistema jurídico en el Estado de Santander: 1857-1886, tomo I, Bucaramanga, Universidad Industrial de Santander, 2008.

Melossi, Darío y Pavarini, Massimo, Cárcel y Fábrica, los Orígenes del Sistema Penitenciario, Siglos XVI-XIX, Bogotá, Editorial Siglo XXI, 1985.

Middendorf, Wolf, Estudios de Criminología Histórica, Madrid, Espasa-Calpe, 1983.

Montovani, Fernando, El Siglo XIX y las Ciencias Criminales, Temis, Bogotá, 1998.

Ocampo López, Javier, “José Ignacio de Márquez, El Civilista”, en Credencial Historia n. ${ }^{\circ} 45$, Bogotá, Septiembre de 1993, pp.10-17.

Olmo, Rosa de, América Latina y su Criminología, Buenos Aires, Editorial Siglo XxI, 1984.

Ots Capdequi, José María, El Estado español en las Indias, México, FCE, 1957.

Palacios, Marco, Parábola del liberalismo, Bogotá, Ed. Norma, 2002. 
Parada García, Gilberto Enrique, “Orden y Revolución en le Ley Penal Colombiana. Un Debate Historiográfico", en Anuario Colombiano de Historia Social y de la Cultura vol.36, n. ${ }^{\circ}$ 2, Bogotá, Universidad Nacional, 2009, pp.177-205.

Parada García, Gilberto Enrique, Ley formal y ley material: la ley penal y su codificación en la construcción del Estado colombiano, 1819-1837, Tesis de Maestría, Departamento de Historia, Universidad Nacional de Colombia, Bogotá, 2011.

Paredes, Julián de, Recopilación de leyes de los reynos de las indias, mandadas imprimir, y publicar por la majestad católica del rey Don Carlos II nuestro señor en Madrid, año de 1681, Madrid, Ediciones Cultura Hispánica, 1973.

Patiño Millán, Beatriz, Criminalidad, ley penal y estructura social en la provincia de Antioquia, 1750-1820, Medellín, IDEA, 1994.

Patiño Millán, Beatriz, "Las mujeres y el crimen en la época colonial. El caso de la ciudad de Antioquia", en Las mujeres en la historia de Colombia, tomo II, Bogotá, Presidencia de la República-Editorial Norma, 1995, pp.77-119.

Peñas Felizzola, Aura Helena, "Utilitarismo y Tradicionalismo en la Legislación Penal Republicana: el Código de 1837”, en Revista Colombiana de Sociología n. 26, Bogotá, Universidad Nacional, 2006, pp.9-42.

Sánchez, Ismael, de la Hera, Alberto y Díaz, Carlos, Historia del Derecho Indiano, Madrid, Editorial Mapfre, 1992.

Sedeillán, Gisela, "Los delitos sexuales: la ley y la práctica judicial en la provincia de Buenos Aires durante el periodo de codificación del derecho penal argentino (18771872)”, en Historia Crítica n. ${ }^{\circ}$ 37, Bogotá, Universidad de los Andes, 2009, pp. 100119.

Tomás y Valiente, Francisco, El Derecho Penal de la Monarquía Absoluta. Siglos XVI, XVII y XVIII, Madrid, Tecnos, 1969.

Uribe-Urán, Víctor Manuel, “Derecho y cultura durante la 'era de la revolución’ en México, Colombia y Brasil, 1750-1850: La Génesis de lo público y lo privado”, en María Teresa Calderón y Clément Thibaud (coords.), Las revoluciones del Mundo Atlántico, Bogotá, Universidad Externado de Colombia / Taurus, 2006.

Uribe Urán, Víctor Manuel, Vidas honorables. Abogados, familias y política en Colombia: 1780-1850, Medellín, EAFIT / Banco de la República, 2008.

Vargas Lesmes, Julián, La sociedad de Santafé Colonial, Bogotá, CINEP, 1990. 
Vega Umbasia, Leonardo Alberto, Pecado y delito en la colonia. La bestialidad como una forma de contravención sexual (1740-1808), Bogotá, Instituto Colombiano de Cultura Hispánica, 1994.

Vela Correa, Andrés Mauricio, De las instituciones penales y los juicios criminales en la colonia neogranadina (1718-1810), tesis de grado, Departamento de Filosofía, Facultad de Ciencias Jurídicas, Pontificia Universidad Javeriana, Bogotá, 2000.

Villegas del Castillo, Catalina, Del hogar a los juzgados. Reclamos familiares en los juzgados superiores en el tránsito de la colonia a la republica: 180o-1850, Bogotá, Universidad de los Andes, 2006.

Zaffaroni, Raúl y Rivacoba, Manuel, Siglo y medio de codificación penal en Iberoamérica, Valparaíso, Ed. Edeval, 1980. 